\title{
Combined posterior contusion and penetrating injury in the pig eye. III. A controlled treatment trial of vitrectomy
}

\author{
ZDENEK GREGOR AND STEPHEN J. RYAN \\ From the Department of Ophthalmology, University of Southern California, Estelle Doheny Eye Foundation, \\ Los Angeles, California, USA
}

SUMMARY A controlled trial of vitrectomy following combined experimental posterior contusion and penetrating eye injury was performed on a group of pigs at 1 day, 2 weeks, and at 10 weeks after the initial injury. Severe intraoperative haemorrhage occurred in 5 eyes operated on at 1 day after injury and in one eye operated on at 2 weeks after injury, but no haemorrhage occurred when surgery was performed 10 weeks after injury.

Until recently penetrating injury of the posterior segment has had a uniformly poor prognosis, mainly because of the development of retinal detachment. ${ }^{1}$ Improved results of treatment have been reported since the application of vitrectomy, ${ }^{2-7}$ but the timing of surgery remains a subject of controversy. ${ }^{38-10}$ While some authors ${ }^{89}$ have reported favourable results following vitrectomy performed within 3 days after injury, it has been our clinical impression as well as that of others ${ }^{36}$ that such early vitrectomy for severe penetrating injury to the eye may be complicated by massive intraoperative haemorrhage. Such haemorrhage is probably related to the ocular contusion $^{11}$ that almost invariably accompanies severe penetrating eye injuries.

Investigators have been unable to establish a randomised, controlled trial of the treatment of penetrating eye injuries in man..$^{4-10}$ Nevertheless, several studies with animal experiments have suggested that vitrectomy may prevent intravitreous fibrous proliferation ${ }^{10} 12$ and the development of traction retinal detachment. ${ }^{1314}$ None of these earlier models, however, contain contusive as well as penetrating components of injury.

In an attempt to elucidate the role of contusion and its relation to the timing of vitrectomy in severe perforating eye injury we developed an experimental model in the pig eye in which a combined contusion and penetrating injury reproduced the results of uveal

Correspondence to Stephen J. Ryan. MD. USC School of Medicine. 1355 San Pablo Street. Los Angeles. California 90033, USA. engorgement, haemorrhage from choroidal vessels, and localised traction in retinal detachment. ${ }^{15}$

In this paper we describe the results of a controlled treatment trial of pars plana vitrectomy at 1 day, 2 weeks, and 10 weeks after standard posterior contusion and penetrating injury in the pig eye.

\section{Material and methods}

Forty-two male and female domestic pigs (Sus scrofa) were used for the trial. Under general anaesthesia the right eye of each animal was subjected to a standard posterior contusion and penetrating injury by the method previously described. ${ }^{15}$

After the injury the animals were randomly allocated to a treatment group or a control group. The treatment group had vitrectomy either 1,14 , or 70 days after injury, with 10 animals undergoing surgery at each of these times; the control group also contained 10 animals. To ensure that the surgical experience achieved during the trial was reflected equally in each treatment group, vitrectomies were performed in a repeated sequence so that 1-day vitrectomy was followed by a 14-day vitrectomy, followed by a 70-day vitrectomy, throughout the trial.

The injured eyes were prepared for surgery in the manner previously described. ${ }^{15}$ The vitrectomy instrument employed was the Ocutome system and the surgical technique was identical to that for vitrectomy in human eyes.

For vitrectomy a $360^{\circ}$ conjunctival perimetry was made, and traction sutures were placed under the 
Table 1 Retinal detachment before and 4 months after vitrectomy

\begin{tabular}{|c|c|c|c|c|c|c|c|c|c|}
\hline \multirow[t]{2}{*}{$\begin{array}{l}\text { Vitrectomy } \\
\text { after injury }\end{array}$} & \multirow[t]{2}{*}{$\begin{array}{l}\text { Number } \\
\text { of eyes }\end{array}$} & \multicolumn{2}{|c|}{$\begin{array}{l}\text { Anterior folds } \\
\text { only }\end{array}$} & \multicolumn{2}{|c|}{$\begin{array}{l}\text { Anterior and posterior } \\
\text { folds }\end{array}$} & \multicolumn{2}{|c|}{$\begin{array}{l}\text { Posterior folds } \\
\text { only }\end{array}$} & \multicolumn{2}{|c|}{$\begin{array}{l}\text { Subtotal/total } \\
\text { detachment }\end{array}$} \\
\hline & & Preop. & 4 months & Preop. & 4 months & Preop. & 4 months & Preop. & 4 months \\
\hline Day 1 & 9 & 6 & - & - & - & - & 4 & - & 2 \\
\hline Day 14 & 9 & 2 & - & 6 & - & 1 & 2 & - & 2 \\
\hline Day 70 & 10 & - & - & - & - & 10 & 4 & - & 3 \\
\hline Controls & 9 & - & - & - & - & - & 6 & - & 1 \\
\hline
\end{tabular}

superior and inferior rectus muscles. Sclerotomy sites were prepared in the inferonasal, superonasal, and superotemporal quadrants $2.5 \mathrm{~mm}$ from the limbus. The infusion terminal was inserted through the pars plana in the inferonasal quadrant. The vitrectomy instrument was introduced through the superotemporal sclerotomy, and a 20 gauge needle was inserted through the superonasal sclerotomy. A lensectomy was performed, followed by anterior vitrectomy. Posterior vitrectomy was done by a bimanual technique and a corneal contact lens. All vitreous blood and gel were removed, and the vitreous was excised within $1-2 \mathrm{~mm}$ from the anterior retina and the ciliary body by scleral indentation techniques. Peeling of the posterior hyaloid face from the retinal surface was attempted in all the eyes. Following vitrectomy the sclerotomies were closed with interrupted 8-0 monofilament nylon sutures. The peripheral retina was then examined for tears or dialyses by indirect ophthalmoscopy and scleral indentation.

In eyes with posterior retinal breaks transcleral cryopexy was performed. Peripheral retinal breaks were treated by cryotherapy and scleral buckling with either a $5 \mathrm{~mm}$ Silastic sponge or a silicone band and/or fluid-sulphur hexafluoride $\left(\mathrm{SF}_{6}\right)$ gas exchange. The conjunctiva was closed with interrupted $6 / 0$ absorbable sutures, a subconjunctival injection of 20 $\mathrm{mg}$ of gentamicin was given, and atropine sulphate (1\%) drops were instilled; no dressing was applied.

Initially the eyes were examined at weekly intervals with the aid of a biomicroscope, an indirect ophthalmoscope, and/or B-scan ultrasonic scanner and the findings documented by a description, drawings. and/or photographs. Owing to the considerable technical problems associated with handling large numbers of animals, which were rapidly increasing in size, regular weekly examinations became impracticable, and thus the majority of eyes were examined immediately after injury, at the time of vitrectomy, and after enucleation.

Eyes in the treatment groups were enucleated 4 months after vitrectomy and in the control group 4 months after the initial injury. Immediately after enucleation a central corneal button was excised, and the eyes were perfused with cold Karnovsky's fixative for 24 hours. For gross examination the eyes were sectioned along the horizontal meridian through the midpoint of the penetrating injury site. Each half was examined under a dissecting microscope, and a drawing and photographs were made. The eyes were then dehydrated in alcohol, embedded in paraffin. sectioned, and stained by routine methods for light microscopy.

Four animals died during the course of the study.

\section{Results}

\section{VITRECTOMY AT 1 DAY}

Surgery. Preoperatively there was oedema of the temporal third of the corneal stroma. The anterior chamber was frequently filled with blood and fibrin. The lens was clear, and a firm blood clot was situated in the posterior vitreous with a strand of blood extending to the optic disc. In most eyes there were circumferential folds posterior to the injury site, often extending to the equator (Table 1). There was no evidence of separation of posterior vitreous from the retina.

At vitrectomy the vitreous gel and the blood clot were removed easily. Peeling of the posterior hyaloid membrane was attempted in all cases, though it was not possible to separate the vitreous cortex from the posterior pole; in one eye a thin vitreous membrane could be peeled from the retinal periphery. Peripheral retinal breaks were created in 3 eyes.

Intraocular haemorrhage occurred in 5 eyes (Table 2). In 4 the haemorrhage appeared to have originated

Table 2 Operative complications

\begin{tabular}{|c|c|c|c|c|}
\hline \multirow{2}{*}{$\begin{array}{l}\text { Vitrectomy } \\
\text { after injury }\end{array}$} & \multirow{2}{*}{$\begin{array}{l}\text { Number } \\
\text { of eyes }\end{array}$} & \multirow[t]{2}{*}{ Haemorrhage } & \multicolumn{2}{|c|}{ Retinal breaks } \\
\hline & & & $\begin{array}{l}\text { Vitreous } \\
\text { probe }\end{array}$ & Peeling ${ }^{\dagger}$ \\
\hline Day 1 & 9 & 5 & 1 & 2 \\
\hline Day 14 & 9 & 1 & 1 & 1 \\
\hline Day 70 & 10 & - & - & - \\
\hline
\end{tabular}

*Breaks due to vitreous probe.

+Breaks during the peeling of vitreous membranes. 
from the pars plana or anterior choroid at the contusion site and in the other the source of bleeding could not be identified. In only one eye could haemorrhage be controlled with coagulation and increased intraocular pressure; the remainder required fluid-SF 6 gas exchange.

Histology. Examination of gross sections revealed flat retina in 3 eyes, full-thickness posterior traction retinal folds in 4 , and a total retinal detachment in 2 (Table 1). There was marked irregularity and anterior displacement of the ora serrata in 8 eyes. The anterior retina was drawn on to the ciliary body in the region of the injury site as well as in relation to the vitrectomy entry sites.

On microscopical examination a thin layer of cortical vitreous was found to be adherent to the retinal surface. Even in the eye in which we felt that complete posterior vitreous separation had been achieved at the time of vitrectomy cortical vitreous could be identified along the temporal half of the retina.

The presence of full-thickness posterior retinal folds was confirmed in 4 eyes. The first eye with complete retinal detachment had a large dialysis and the anterior retina was adherent to the pupillary margin. The second eye showed total shallow retinal detachment with high posterior folds.

\section{VITRECTOMY AT 2 WEEKS}

Surgery. Preoperatively the anterior segment was quiet in all eyes. The vitreous was reddish-brown in colour and the blood clot was situated in the anterior vitreous, with a stalk of vitreous condensation attaching to the disc. In 2 eyes the clot had almost completely resorbed, allowing a hazy view of the entire fundus. Localised full-thickness retinal folds, in the form of anterior circumferential or posterior radial folds, or both, were present in all the eyes (Table 1).

During surgery vitreous gel was mobile and was easier to cut than in the former group. A thin posterior vitreous membrane could be separated from the retinal surface in most eyes. Two retinal tears were created, one with the vitrectomy instrument and the other during attempted peeling of the posterior vitreous face. Mild haemorrhage occurred from the superonasal sclerotomy in one eye, but this was easily controlled with increased intraocular pressure (Table 2).

Histology. Examination of gross sections showed complete retinal detachment in 2 eyes, and in one there was a large posterior retinal hole which had been created at the time of vitrectomy. In 2 eyes there were full-thickness retinal folds in the posterior pole radiating from the optic disc; in the remaining 5 eyes the retina was flat (Table 1). In 8 eyes the ora serrata was drawn on to the pars plicata of the ciliary body.

Microscopical examination confirmed the presence of retinal detachment and/or posterior retinal folds in 4 eyes. In all but one eye a thin layer of cortical vitreous lined by scattered macrophages was adherent to the retinal surface and to the tips of the retinal folds.

There was moderate fibrocellular proliferation in the region of the penetrating wound and along epiretinal membranes in all the eyes. Transvitreal bands extended from the ciliary body on to the tips of the posterior retinal folds in 2 eyes.

\section{VITRECTOMY AT 10 WEEKS}

Surgery. Before vitrectomy the eyes were quiet, although posterior synechiae were present in 4 eyes. The vitreous was slightly hazy but devoid of blood clots. All the eyes contained posterior retinal folds, which often extended to the periphery.

During vitrectomy the vitreous was mobile and easily removed. Frequently there were vitreous condensations attached to the disc and to the tip of the retinal folds. Peeling of the posterior vitreous face was attempted in all eyes; this appeared to be successful, at least in part, in 8 eyes.

Histology. Three eyes in this group developed total retinal detachment and posterior folds were found in 4 ; the retina was flat in the remaining 3 eyes (Table 1 ). Anterior retinal oral distortion occurred in all but one of the eyes.

On microscopical examination posterior hyaloid face could not be identified on the posterior retinal surface in 2 eyes. In the remainder a thin layer of vitreous cortex was seen lining the entire retina.

The degree of fibrocellular proliferation at the inner aspect of the perforating injury, on the retinal surfaces, and in the form of transvitreal bands, was similar to that seen in eyes operated on 14 days after injury.

\section{CONTROL GROUP}

In the 12 control eyes there was only one case of total retinal detachment. Six of the remaining eyes had full-thickness posterior retinal folds, while the retina remained flat in the others (Table 1). Anterior displacement of the ora serrata occurred in three eyes.

Microscopical examination, however, revealed greater fibrous proliferation at the site of penetrating injury than seen in any of the treatment groups. Fibrocellular transvitreal bands connecting the posterior retinal folds to the site of penetrating trauma occurred in 2 eyes.

\section{Discussion}

The results of this study confirm the clinical impressions ${ }^{316}{ }^{17}$ that early vitrectomy for penetrating 
injuries with significant contusive components may be complicated by severe intraoperative haemorrhage and that this is less likely to occur if surgical intervention is delayed until a time when the effects of contusion begin to recede.

In this experiment intraocular haemorrhage occurred in 5 out of 9 eyes operated on within 24 hours after injury; this bleeding was difficult to control and precluded a satisfactory completion of the operation. In contrast operative haemorrhage occurred only in one eye operated on 2 weeks after the injury. In these eyes the source of bleeding was difficult to identify, but it appeared to have originated from the pars plana sclerotomies. It has been previously shown that after contusion the pars plana and the anterior choroid become swollen, with evidence of vascular engorgement and choroidal haemorrhage ${ }^{18}$ Lowering of the intraocular pressure at the time of vitrectomy combined with extensive intraocular manipulations may give rise to profuse bleeding from vessels which were severed at the time of the injury ${ }^{9}$ or which became atonic ${ }^{19}$ soon afterwards. However, 2 weeks after contusion there is little or no evidence of such changes in the anterior uvea, ${ }^{18}$ and the risk of intraoperative haemorrhage is consequently less.

In this model extensive retinal detachment does not result from a combined contusion and penetrating injury; rather the detachment takes the form of fullthickness retinal folds. ${ }^{15}$ This makes the results of our present study difficult to compare with those of previous experiments in primates, in which similar penetrating injury resulted in posterior vitreous separation and extensive retinal detachment. ${ }^{13}{ }^{14}$ The lack of retinal detachment in the pig may be due to different anatomical ${ }^{15}$ and functional ${ }^{18}$ characteristics of the pig vitreous or a faster rate of absorption of blood from the pig eye or a combination of these factors. In this trial vitrectomy often resulted in the flattening of pre-existing retinal folds, but new areas of localised retinal detachment appeared in different locations over the next 4 months. Histologically the new retinal folds were associated with posterior cortical vitreous attached to the crests of the retinal folds. This underlines the importance in the clinical setting of performing as complete a vitrectomy as possible, removing the posterior hyaloid scaffold, and thus preventing retinal detachment in areas of vitreoretinal adherence.

The results of this study support the conclusions of our previous experiments in the pig. ${ }^{15} 18$ These suggested that there may be a period of time after severe posterior segment injury during which the acute effects of contusion are subsiding and the fibroproliferative effects of ocular penetration have not yet become established and thus may still be amenable to treatment. Although in the pig eye we did not achieve surgical end-results comparable to those of our previous monkey experiments, ${ }^{1314}$ we feel that information of considerable clinical value was obtained by this study in that our results support our clinical experience that vitrectomy is best avoided during the first week after a severe posterior penetrating eye injury.

We thank Kate Borkowski and her colleagues for technical assistance and Sue Gertson for secretarial help.

This study was supported in part by NIH grant EY 02061 and EY 03040 (Dr Ryan).

\section{References}

1 Eagling EM. Perforating in juries involving the posterior segment. Trans Ophthalmol Soc UK 1975; 95: 335.

2 Machemer R, Norton EWD. A new concept for vitreous surgery. 3. Indications and results. Am J Ophthalmol 1972; 74: 1034-56.

3 Ryan SJ. Allen AW. Pars plana vitrectomy in ocular trauma. Am J Ophthalmol 1979; 88: 483-91.

4 Hutton WL, Snyder WB. Vaiser A. Vitrectomy in the treatment of ocular perforating injuries. Am J Ophthalmol 1976; 81: 733-9.

5 Benson WE, Machemer R. Severe perforating injuries treated with pars plana vitrectomy. Am J Ophthalmol 1976; 81: 728-32.

6 Conway BP, Michels RG. Vitrectomy techniques in the management of selected penetrating ocular injuries. Ophthalmology 1978; 85: 560-83.

7 Aaberg TM, Van Horn DL. Late complications of pars plana vitreous surgery. Ophthalmology 1978; 85: 125-40.

8 Faulborn J, Atkinson A, Olivier D. Primary vitrectomy as a preventive surgical procedure in the treatment of severely injured eyes. Br J Ophthalmol 1977; 61: 202-8.

9 Coleman DJ. Early vitrectomy in the management of the severely traumatized eye. Am J Ophthalmol 1982; 93: 543-51.

10 Abrams GW. Topping TM. Machemer R. Vitrectomy for injury: the effect on intraocular proliferation following perforation of the posterior segment of the rabbit eye. Arch Ophthalmol 1979; 97 : 743-8.

11 Eagling EM. Ocular damage after blunt trauma to the eye. Its relationship to the nature of the injury. Br J Ophthalmol 1974; 58: 126-40.

12 Gregor Z, Ryan SJ. The comparison of complete and core vitrectomies in the treatment of experimental posterior penetrating eye injury in the rhesus monkey: II. Histologic features. Arch Ophthalmol in press.

13 Cleary PE, Ryan SJ. Vitrectomy in penetrating eye injury. Results of a controlled trial of vitrectomy in an experimental posterior penetrating eye injury in the rhesus monkey. Arch Ophthalmol 1981; 99: 287-92.

14 Gregor Z, Ryan SJ. A comparison of complete and core vitrectomies in the treatment of experimental posterior penetrating eye injury in the rhesus monkey: I. Clinical features. Arch Ophthalmol in press.

15 Gregor Z, Ryan SJ. Combined posterior contusion and penetrating injury in the pig eye: I. A natural history study. $B r J$ Ophthalmol 1982; 66: 793-8.

16 Michels RG. Indications and results. In: Vitreous surgery. St Louis: Mosby, 1981: 275.

17 Charles S. Trauma. In: Vitreous microsurgery. Baltimore: Williams and Wilkins, 1981: 144.

18 Gregor Z, Ryan SJ. Combined posterior contusion and penetrating injury in the pig eye: II. Histological features. BrJOphthalmol 1982; 66: 799-804.

19 Duke-Elder S. MacFaul PA. Concussions and contusions. In: Duke-Elder, ed. System of ophthalmology. St Louis: Mosby. 1972: 14 (Part 1): 73. 